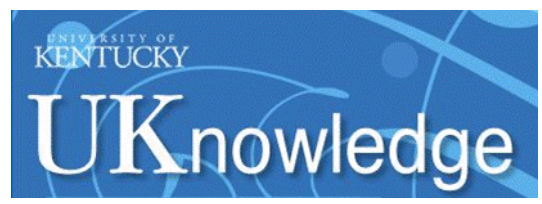

University of Kentucky

UKnowledge

\title{
Cervical Screening and General Physical Examination Behaviors of Women Exposed In Utero to Diethylstilbestrol
}

\author{
Elizabeth A. Camp \\ University of Texas Health Science Center at Houston \\ Ann L. Coker \\ University of Kentucky, ann.coker@uky.edu \\ Rebecca Troisi \\ National Cancer Institute, troisir@mail.nih.gov \\ Stanley J. Robboy \\ Duke University, Stanley.Robboy@duke.edu \\ Kenneth L. Noeller \\ University of Massachusetts Medical School Worcester
}

See next page for additional authors

Follow this and additional works at: https://uknowledge.uky.edu/crvaw_facpub

Part of the Obstetrics and Gynecology Commons, and the Public Health Commons

Right click to open a feedback form in a new tab to let us know how this document benefits you.

\section{Repository Citation}

Camp, Elizabeth A.; Coker, Ann L.; Troisi, Rebecca; Robboy, Stanley J.; Noeller, Kenneth L.; Goodman, Karen J.; Titus-Ernstoff, Linda T.; Hatch, Elizabeth E.; Herbst, Arthur L.; Kaufman, Raymond H.; and Adam, Ervin, "Cervical Screening and General Physical Examination Behaviors of Women Exposed In Utero to Diethylstilbestrol" (2008). CRVAW Faculty Journal Articles. 140.

https://uknowledge.uky.edu/crvaw_facpub/140

This Article is brought to you for free and open access by the Center for Research on Violence Against Women at UKnowledge. It has been accepted for inclusion in CRVAW Faculty Journal Articles by an authorized administrator of UKnowledge. For more information, please contact UKnowledge@lsv.uky.edu. 


\title{
Cervical Screening and General Physical Examination Behaviors of Women Exposed In Utero to Diethylstilbestrol
}

\author{
Digital Object Identifier (DOI) \\ http://dx.doi.org/10.1097/LGT.0b013e31815ae980 \\ Notes/Citation Information \\ This manuscript provided with permission from the publisher, and also accessible through the journal's \\ website at http://journals.Iww.com/jlgtd/Abstract/2008/04000/ \\ Cervical_Screening_and_General_Physical.7.aspx.
}

\section{Authors}

Elizabeth A. Camp, Ann L. Coker, Rebecca Troisi, Stanley J. Robboy, Kenneth L. Noeller, Karen J. Goodman, Linda T. Titus-Ernstoff, Elizabeth E. Hatch, Arthur L. Herbst, Raymond H. Kaufman, and Ervin Adam 


\section{Cervical Screening and General Physical Examination Behaviors of Women Exposed In Utero to Diethylstilbestrol}

Elizabeth A. Camp, MSPH, ${ }^{1}$ Ann L. Coker, PhD,${ }^{1}$ Rebecca Troisi, ScD, ${ }^{2}$ Stanley J. Robboy, MD ${ }^{3}$ Kenneth L. Noller, MD ${ }^{4}$ Karen J. Goodman, PhD, ${ }^{1}$ Linda T. Titus-Ernstoff, PhD,${ }^{5}$ Elizabeth E. Hatch, PhD, ${ }^{6}$ Arthur L. Herbst, MD, ${ }^{7}$ Raymond H. Kaufman, MD, ${ }^{8,9}$ and Ervin Adam, MD ${ }^{8,10}$

${ }^{1}$ School of Public Health, University of Texas Health Science Center, Houston, TX, ${ }^{2}$ Division of Cancer Epidemiology and Genetics, National Cancer Institute, Bethesda, MD, ${ }^{3}$ Departments of Pathology and Obstetrics and Gynecology, Duke University Medical Center, Durham, NC,

${ }^{4}$ Department of Obstetrics and Gynecology, University of Massachusetts Medical Center,

Worcester, MA, ${ }^{5}$ Norris Cotton Cancer Center, Dartmouth-Hitchcock Medical Center,

Lebanon, NH, ${ }^{6}$ Department of Epidemiology and Biostatistics, Boston University School

of Public Health, Boston, MA, ${ }^{7}$ Department of Obstetrics and Gynecology, University of Chicago, Chicago, IL, ${ }^{8}$ Department of Obstetrics and Gynecology, Baylor College of Medicine, Houston, TX, ${ }^{9}$ Department of Obstetrics and Gynecology, Methodist Hospital, Houston, TX, and ${ }^{10}$ Department of Molecular Virology and Microbiology, Baylor College of Medicine, Houston, TX

\begin{abstract}
Objective. To estimate whether women exposed in utero to diethylstilbestrol (DES) report receiving more cervical and general physical examinations compared to unexposed women.

Materials and Methods. 1994 Diethylstilbestrol Adenosis cohort data are used to assess the degree of recommended compliance of cervical screenings found in 3,140 DESexposed and 826 unexposed women. Participants were enrolled at 4 sites: Houston, Boston, Rochester, and Los Angeles. Logistic regression modeling was used to analyze mailed questionnaire data, which included reported frequency over the preceding 5 years (1990-1994) of Papanicolaou smears and general physical examinations.
\end{abstract}

Reprint requests to: Raymond H. Kaufman, MD, 6550 Fannin, Suite 900 Houston, TX 77030. E-mail: rkaufman@tmh.tmc.edu

This study was supported by the National Cancer Institute under contract \#1-CP-21166.

(C) 2008, American Society for Colposcopy and Cervical Pathology

Journal of Lower Genital Tract Disease, Volume 12, Number 2, 2008, 111-117
Results. Diethylstilbestrol-exposed women exceeded the recommended frequency of Papanicolaou smear screenings [adjusted odds ratio $(\mathrm{aOR})=2.15,95 \% \mathrm{Cl}$ (confidence interval) $=1.60-2.88]$ compared to the unexposed. This association held among those without a history of cervical intraepithelial neoplasia $(\mathrm{aOR}=1.88$, $95 \% \mathrm{Cl}=1.35-2.62)$. Diethylstilbestrol-exposed women exceeded annual recommendations for physical examinations $(\mathrm{aOR}=2.27,95 \% \mathrm{Cl}=1.16-4.43)$ among women without a history of chronic disease when compared to unexposed women.

Conclusions. Most DES-exposed women are receiving cervical cancer screening at least at recommended intervals, but one third of the women are not receiving annual Papanicolaou smear examinations.

Key Words: diethylstilbestrol, physical examination, vaginal smears

n 1971, a strong association was found between in utero exposure to diethylstilbestrol (DES) and the development of clear cell vaginal and cervical adenocarcinoma 
[1]. Within the same year, DES use was discontinued and no longer prescribed to maintain pregnancies [2]. Shortly thereafter, the National Cancer Institute (NCI) awarded contracts to 4 geographically separated institutions (Houston, Boston, Rochester, and Los Angeles) to study in utero DES-exposed offspring, leading to the creation of the Diethylstilbestrol Adenosis (DESAD) Project [3, 4]. Several studies have focused on cervical and vaginal changes in this exposed population $[3,5,6]$. This current study examines whether DES-exposed women relative to unexposed women are more likely to receive screening for cervical cancer and other health problems at recommended intervals.

\section{MATERIALS AND METHODS}

Patient recruitment has previously been described [3, 4]. Briefly, DES-exposed women were recruited through record review, physician referral, or walk-ins. The unexposed women were recruited from available medical records and from siblings of exposed women, matched on exposed women's ages within 6 months and on mothers' ages during pregnancy within 5 years. At the start of 1975 through 1983, both exposed and unexposed women were examined annually and then followed yearly with a questionnaire from 1984 to 1989 $[6,7]$. Again in 1994, self-administered questionnaires were mailed to previous DESAD participants [7]. This study has been reviewed and approved by institutional review boards at each participating study site.

Information describing screening behaviors was obtained from the 1994 questionnaire, including the number of Papanicolaou smears and the number of general physical examinations (GPEs).

Women reported the frequency of Papanicolaou smear screening in the past 5 years in the following ordinal categories: none, once, 2 to 3 times, 4 to 5 times, and more than 5 times. The Department of Health, Education, and Welfare in 1978, the NCI in 1980, and the American College of Obstetricians and Gynecologists in 1994 recommended annual gynecological examinations for DES-exposed women [8-10]. The recommendation for Papanicolaou smear screening for asymptomatic DES-exposed women includes not only the cervical cytology examination but also an extensive vaginal examination, with screening beginning at age 14,4 years earlier than the recommendation age for unexposed women $[8,10]$.

Compliance was defined as receiving 4 to 5 Papanicolaou smears in the past 5 years, whereas receiving more than 5 was defined as exceeding recommendations. These 2 groups were compared with those with fewer than 4 Papanicolaou smears in the past 5 years, which was considered noncompliant. Women with hysterectomies were excluded from the Papanicolaou smear analysis.

For the physical examination component, compliance was defined as having a GPEs 4 to 5 times in the past 5 years, and more than 5 was defined as exceeding recommendations. The reference group was fewer than 4 to 5 examinations in the past 5 years. Annual examinations were categorized as compliant, even though periodic examinations (ranging from once to every 4 years based on age and gender) are recommended by the American College of Physicians and the American Medical Association [11]. However, the reviewed literature at this time has shown that patients expect a complete annual examination, and physicians comply at such a request [12]. Furthermore, setting the compliance level at a yearly examination allowed for more straightforward comparisons across ages in the study population.

The analysis addressed the association between DES exposure and reported frequency of cervical cancer screening and GPEs. Because a personal history of cervical intraepithelial neoplasms (CIN) may result in more frequent Papanicolaou smear screening, the analyses were stratified to assess whether such a history modified the association between DES exposure and frequency of Papanicolaou smear screening. Similarly, women with a chronic disease may be more likely to receive more frequent physical examinations, so the association between DES exposure and frequency of physical examinations was conducted separately by those who did and did not have 1 or more of the specified chronic diseases listed in Table 1. All statistical evaluation was performed using SPSS 11.0 statistical software (SPSS, Inc., Chicago, IL) and EpiInfo 6.04d (Geneva, Switzerland).

Although the parent study used a prospective cohort design, odds ratios (OR) were chosen as the relevant measure of association between DES exposure status and screening frequency in the past 5 years. The dependent outcome variables had 3 frequency levels. Separate binary (i.e., compliant vs. noncompliant and exceeding recommendations vs. noncompliant) logistic regression models were used to estimate the ORs and $95 \%$ confidence intervals (CI) for each of the 2 outcome categories that met or exceeded recommendations compared to the reference category [13]. 
Table 1. Comparison of Exposed and Unexposed Women From the 1994 DESAD Cohort Study in Demographic and Other Factors Associated With Gynecological Screening and Physician Visits

\begin{tabular}{|c|c|c|c|c|}
\hline & \multicolumn{2}{|c|}{$\begin{array}{l}\text { DES Exposed } \\
(\mathrm{n}=3,140)\end{array}$} & \multicolumn{2}{|c|}{$\begin{array}{c}\text { DES } \\
\text { Unexposec } \\
(n=826)\end{array}$} \\
\hline & No. & $\%$ & No. & $\%$ \\
\hline \multicolumn{5}{|l|}{ Age, y } \\
\hline $25-29$ & 50 & 2 & 0 & 0 \\
\hline $30-34$ & 354 & 11 & 30 & 4 \\
\hline $35-39$ & 877 & 28 & 263 & 32 \\
\hline $40-44$ & 1,296 & 41 & 301 & 36 \\
\hline $45-49$ & 533 & 17 & 200 & 24 \\
\hline $50-55$ & 30 & 1 & 32 & 4 \\
\hline \multicolumn{5}{|l|}{ Education } \\
\hline $\begin{array}{l}\text { Less than high school } \\
\text { and post-high school }\end{array}$ & 402 & 13 & 152 & 18 \\
\hline Junior college & 724 & 23 & 197 & 24 \\
\hline 4-Year college & 1,125 & 36 & 257 & 31 \\
\hline Graduate school & 880 & 28 & 217 & 26 \\
\hline Missing & 9 & 0.3 & 3 & 0. \\
\hline \multicolumn{5}{|l|}{ Marital status } \\
\hline Single & 410 & 13 & 113 & 14 \\
\hline Married & 2,261 & 72 & 591 & 72 \\
\hline Widowed/divorced/separated & 425 & 14 & 105 & 13 \\
\hline Missing & 44 & 1 & 17 & 2 \\
\hline \multicolumn{5}{|l|}{ Site } \\
\hline Boston & 921 & 29 & 321 & 39 \\
\hline Mayo & 588 & 19 & 186 & 23 \\
\hline California & 803 & 26 & 172 & 21 \\
\hline Baylor & 828 & 26 & 147 & 18 \\
\hline \multicolumn{5}{|l|}{ History of $\mathrm{CIN}^{a}$} \\
\hline Yes & 672 & 21 & 64 & 8 \\
\hline No & 2,058 & 66 & 661 & 80 \\
\hline Missing & 410 & 13 & 101 & 12 \\
\hline \multicolumn{5}{|l|}{ History of an abnormal Pap smear ${ }^{a}$} \\
\hline Yes & 1,162 & 37 & 178 & 22 \\
\hline No & 1,588 & 51 & 535 & 65 \\
\hline Missing & 390 & 12 & 113 & 14 \\
\hline \multicolumn{5}{|c|}{$\begin{array}{l}\text { History of diagnosis (ever) } \\
\quad \text { with a sexually transmitted infection }{ }^{b}\end{array}$} \\
\hline Yes & 713 & 23 & 158 & 19 \\
\hline No & 2,427 & 77 & 668 & 81 \\
\hline \multicolumn{5}{|l|}{ History of chronic disease ${ }^{c}$} \\
\hline Yes & 890 & 28 & 233 & 28 \\
\hline No & 2,250 & 72 & 593 & 72 \\
\hline
\end{tabular}

DESAD, Diethylstilbestrol Adenosis; DES, diethylstilbestrol; CIN, cervical intraepithelial neoplasms.

${ }^{a}$ Women with hysterectomies were excluded from this comparison $(N=415$; exposed $=322$ and unexposed $=93$ ); the Yates 2-sided $p$ value comparing the prevalence of hysterectomy in exposed and unexposed is 0.44 .

${ }^{b}$ Sexually transmitted infections include a diagnosis of any of the following: herpes, HIV,

chlamydia, genital warts, or syphilis.
'Chronic disease includes a diagnosis of any of the following: lupus erythematosus, scleroderma, rheumatoid arthritis, multiple sclerosis, chronic ulcerative colitis, regional enteritis, insulin-dependent diabetes mellitus, thyrotoxicosis, thyroiditis, hyperthyroidism, pernicious anemia, idiopathic thrombocytopenic purpura, Addison disease, Behçet syndrome, temporal arteritis, optic neuritis, asthma, chronic fatigue syndrome, congenital abnormalities (spine/skeleton), or a diagnosis/treatment for depression /mental illness.

Potential confounders for exposure-outcome associations assessed in this study included age (in 5-year categories), marital status (single, married, or widowed/ divorced/separated), education (high school and posthigh school, junior college, full college, and graduate school), and study site. All of these were included in the final models as their inclusion resulted in a $10 \%$ or greater change between the crude and adjusted estimates for the exposure-outcome association when comparing the crude and adjusted associations [14]. The BreslowDay test for homogeneity was used to determine whether the association between DES exposure and screening behaviors differed by history of CIN or chronic disease. A 2 -sided $p$ value of .25 or less was considered evidence of effect-measure modification [13].

The Yates 2-sided $p$ value was used to test differences in screening frequency between exposed and unexposed women. Unconditional logistic regression was used to estimate adjusted prevalence ORs for DES and the categories of screening frequency levels. The ordinal variable indicating screening frequency was included in logistic models to assess whether DES exposure was associated with a trend toward increased screening frequency; the Wald 2-sided $p$ value test was presented [15].

\section{RESULTS}

Response rates for the 1994 questionnaire were high for all centers: $96 \%$ of the exposed and $98 \%$ of the unexposed women at the Boston Center, $96 \%$ of both exposed and unexposed women at the Rochester Center, $84 \%$ of the exposed and $91 \%$ of the unexposed at the California Center, and $89 \%$ of the exposed and $83 \%$ of the unexposed women at the Baylor Center.

The total number of study participants who responded to the 1994 questionnaire included 3,140 exposed women and 826 unexposed women, 98\% of whom were Caucasian. Among the exposed women who responded to the 1994 questionnaire, $46 \%$ were originally recruited into the cohort through record review, 33\% through physician referral, and $21 \%$ were walk-ins. In the unexposed population, $75 \%$ were recruited through record review and $25 \%$ were siblings of exposed women.

Diethylstilbestrol-exposed women were similar to unexposed women on study variables with the following exceptions (Table 1): unexposed women were older (unexposed mean age $=42$ years, and DES-exposed mean age $=40$ years; Yates 2 -sided $p<.0001)$, whereas DESexposed women were more highly educated $(p<.0001)$ than unexposed women (those whose education did not exceed high school, including nongraduates, and those with post-high school vocational training were compared to those with the higher levels of junior college through graduate school). There was no significant difference between exposed and unexposed women 
Table 2. Adjusted Odds Ratios and 95\% Confidence Interval for Pap Smear Visits in the Past 5 Years (1990-1994) for DESAD Exposed and Unexposed Women With Intact Uteri

\begin{tabular}{|c|c|c|c|c|c|c|c|}
\hline & \multicolumn{2}{|c|}{$\begin{array}{l}\text { DES Exposed } \\
(n=2,818)\end{array}$} & \multicolumn{2}{|c|}{$\begin{array}{c}\text { DES } \\
\text { Unexposed } \\
(n=733)\end{array}$} & \multirow[b]{2}{*}{ Adjusted $\mathrm{OR}^{b}$} & \multirow[b]{2}{*}{$95 \% \mathrm{Cl}$} & \multirow[b]{2}{*}{$p$ for trend } \\
\hline & No. & $\%$ & No. & $\%$ & & & \\
\hline \multicolumn{8}{|c|}{ No. of Pap smear visits in past 5 years ${ }^{a}$} \\
\hline Missing $^{d}$ & 7 & 0.2 & 8 & 1 & & & \\
\hline None & 60 & 2 & 17 & 2 & & & \\
\hline Once & 167 & 6 & 52 & 7 & & & \\
\hline $2-3$ times $^{e}$ & 601 & 21 & 186 & 25 & 1.00 & REF & \\
\hline 4-5 times $^{f}$ & 1,381 & 49 & 393 & 54 & 1.05 & $0.87-1.27$ & \\
\hline$>5$ times $^{g}$ & 602 & 21 & 77 & 11 & 2.15 & $1.60-2.88$ & $<0.001$ \\
\hline \multicolumn{8}{|c|}{ Reported history of CIN ( $n=732$ ) } \\
\hline & \multicolumn{2}{|c|}{$\begin{array}{l}\text { DES exposed } \\
\quad(n=668)\end{array}$} & \multicolumn{2}{|c|}{$\begin{array}{c}\text { DES } \\
\text { unexposed } \\
(n=64)\end{array}$} & & & \\
\hline None & 7 & 1 & 0 & 0 & & & \\
\hline Once & 31 & 5 & 1 & 2 & & & \\
\hline $2-3$ times $^{e}$ & 102 & 15 & 9 & 14 & 1.00 & REF & \\
\hline 4-5 times $^{f}$ & 296 & 44 & 36 & 56 & 0.48 & $0.22-1.02$ & \\
\hline$>5$ times $^{g}$ & 232 & 35 & 18 & 28 & 0.75 & $0.32-1.77$ & 0.33 \\
\hline \multicolumn{8}{|c|}{ Reported no history of CIN $(n=2,709)$} \\
\hline & \multicolumn{2}{|c|}{$\begin{array}{l}\text { DES exposed } \\
(n=2,056)\end{array}$} & \multicolumn{2}{|c|}{$\begin{array}{l}\text { DES } \\
\text { unexposed } \\
(n=653)\end{array}$} & & & \\
\hline None & 52 & 3 & 16 & 3 & & & \\
\hline Once & 133 & 7 & 51 & 8 & & & \\
\hline $2-3$ times $^{e}$ & 485 & 24 & 175 & 27 & 1.00 & REF & \\
\hline 4-5 times $^{f}$ & 1,040 & 51 & 353 & 54 & 1.05 & $0.86-1.29$ & \\
\hline$>5$ times $^{g}$ & 346 & 17 & 58 & 9 & 1.88 & $1.35-2.62$ & 0.002 \\
\hline \multicolumn{8}{|c|}{$\begin{array}{l}\text { DESAD, Diethylstilbestrol Adenosis; DES, diethylstilbestrol; OR, odds ratio; } \mathrm{Cl} \text {, confidence interval; } \mathrm{CIN} \text {, cervical intraepithelial neoplasia; REF, reference group. } \\
\text { a Women with previous hysterectomies were removed from the analysis }(\mathrm{N}=415 ; \text { exposed }=322 \text {, unexposed = } 93 \text { ). } \\
{ }^{b} \text { Adjusted for age (continuous variable), education, marital status, and study site. } \\
\text { 'The } p \text { value (2-sided) for trend included all } 5 \text { outcome frequency categories; none of the frequency categories were combined for the trend test. } \\
{ }^{d} \text { Missing values indicate a nonresponse to the question regarding number of Pap smear visits in the past } 5 \text { years. } \\
{ }^{e} \text { Categories (none, once, and } 2-3 \text { times) were combined to form the reference category. } \\
{ }^{f} \text { The category } 4-5 \text { times was compared with the reference group and defined as compliant for annual Pap smear screening. } \\
\text { gThe category more than } 5 \text { times was compared with the reference group and defined as exceeding recommendations for annual Pap smear screening. }\end{array}$} \\
\hline
\end{tabular}

regarding marital status $(p=.98)$. However, DES-exposed women were more likely to report having a history of CIN $(p<.0001)$ than unexposed women, history of an abnormal Papanicolaou smear $(p<.0001)$, and a diagnosis of a sexually transmitted infection (e.g., herpes, HIV, chlamydia, genital warts, or syphilis) $(p=.03)$. There was no significant difference between exposed and unexposed women regarding a history of chronic disease $(p=.97)$, BBD $(p=.94)$, and hysterectomies $(p=.44)$.

Table 2 presents the association between DES exposure and Papanicolaou smear screening frequency. Diethylstilbestrol-exposed women were more likely to exceed recommendations for annual Papanicolaou smear screening [adjusted odds ratio $(\mathrm{aOR})=2.15,95 \% \mathrm{CI}=$ 1.60-2.88]. Among women without a reported history of CIN, DES-exposed women were more likely than unexposed women to exceed recommendations for
Papanicolaou smears $(\mathrm{aOR}=1.88,95 \% \mathrm{CI}=$ $1.35-2.62 ; p$ value for trend $=.002)$, whereas among women with a history of CIN, this was not observed.

Among all women, DES exposure was not associated with receiving more general physical visits. However, among women with no history of chronic disease, DES exposure was positively associated with reporting more than 5 visits in the past 5 years $(\mathrm{aOR}=2.27,95 \% \mathrm{CI}=$ $1.16-4.43 ; p$ value for trend $=.07$ ) (Table 3 ), yet DES exposure was not associated with an increased frequency of GPEs among women with a reported history of a chronic disease.

The analysis was also repeated, removing the women who had never had a screening examination within the past 5 years from the noncompliant group, under the assumption that these women maybe fundamentally different than women who have had at least 1 screening 
Table 3. Adjusted ORs and $95 \%$ Confidence Intervals for General Physical Examinations in the Past 5 Years (1990-1994) in DESAD Exposed and Unexposed Women

\begin{tabular}{|c|c|c|c|c|c|c|c|}
\hline & \multicolumn{2}{|c|}{$\begin{array}{l}\text { DES Exposed } \\
(\mathrm{n}=3,140)\end{array}$} & \multicolumn{2}{|c|}{$\begin{array}{c}\text { DES } \\
\text { Unexposed } \\
(n=826)\end{array}$} & \multirow[b]{2}{*}{ Adjusted OR ${ }^{a}$} & \multirow[b]{2}{*}{$95 \% \mathrm{Cl}$} & \multirow[b]{2}{*}{$p$ for trend ${ }^{b}$} \\
\hline & No. & $\%$ & No. & $\%$ & & & \\
\hline \multicolumn{8}{|c|}{ No. of physical exams in the past 5 years } \\
\hline Missing ${ }^{c}$ & 64 & 2 & 23 & 3 & & & \\
\hline None & 491 & 16 & 113 & 14 & & & \\
\hline Once & 780 & 25 & 211 & 26 & & & \\
\hline $2-3$ times $^{d}$ & 1,005 & 32 & 266 & 32 & 1.00 & REF & \\
\hline 4-5 times $^{e}$ & 641 & 20 & 183 & 22 & 0.96 & $0.79-1.17$ & \\
\hline$>5$ times $^{f}$ & 159 & 5 & 30 & 4 & 1.30 & $0.87-1.96$ & 0.58 \\
\hline \multicolumn{8}{|c|}{ Reported history of chronic disease ${ }^{g}(n=1,105)$} \\
\hline & \multicolumn{2}{|c|}{$\begin{array}{l}\text { DES exposed } \\
\quad(n=878)\end{array}$} & \multicolumn{2}{|c|}{$\begin{array}{l}\text { DES } \\
\text { unexposed } \\
(n=227)\end{array}$} & & & \\
\hline None & 97 & 11 & 27 & 12 & & & \\
\hline Once & 184 & 21 & 43 & 19 & & & \\
\hline $2-3$ times $^{d}$ & 310 & 35 & 78 & 34 & 1.00 & REF & \\
\hline 4-5 times ${ }^{e}$ & 224 & 25 & 59 & 25 & 1.03 & $0.72-1.46$ & \\
\hline$>5$ times $^{f}$ & 63 & 7 & 20 & 9 & 0.81 & $0.47-1.40$ & 0.81 \\
\hline \multicolumn{8}{|c|}{ Reported no history of chronic disease ${ }^{g}(n=2,764)$} \\
\hline & \multicolumn{2}{|c|}{$\begin{array}{l}\text { DES exposed } \\
(n=2,198)\end{array}$} & \multicolumn{2}{|c|}{$\begin{array}{c}\text { DES } \\
\text { unexposed } \\
(n=576)\end{array}$} & & & \\
\hline None & 394 & 18 & 86 & 15 & & & \\
\hline Once & 596 & 27 & 168 & 28 & & & \\
\hline $2-3$ times $^{d}$ & 695 & 31 & 188 & 32 & 1.00 & REF & \\
\hline 4-5 times ${ }^{e}$ & 417 & 19 & 124 & 21 & 0.93 & $0.73-1.17$ & \\
\hline$>5$ times $^{f}$ & 96 & 4 & 10 & 2 & 2.27 & $1.16-4.43$ & 0.07 \\
\hline \multicolumn{8}{|c|}{$\begin{array}{l}\text { DESAD, Diethylstilbestrol Adenosis; DES, diethylstilbestrol; OR, odds ratio; } \mathrm{Cl} \text {, confidence interval; REF, reference group. } \\
\text { a Adjusted for age (continuous variable), education, marital status, and study site. } \\
\text { }{ }^{b} \text { The } p \text { value ( } 2 \text { sided) for trend included all } 5 \text { outcome frequency categories; none of the frequency categories were combined for the trend test. } \\
{ }^{c} \text { Missing values indicate a nonresponse to the question regarding number of general physical examinations in the past } 5 \text { years. } \\
{ }^{d} \text { Categories (none, once and } 2-3 \text { times) were combined to form the reference category. } \\
\text { eThe category } 4-5 \text { times was compared to the reference group and defined as compliant for annual, general physical examinations. } \\
\text { TThe category more than } 5 \text { times was compared to the reference group and defined as exceeding recommendations for annual, general physical examinations. } \\
{ }^{g} \text { Chronic disease includes a diagnosis of any of the following: lupus erythematosus, scleroderma, rheumatoid arthritis, multiple sclerosis, chronic ulcerative colitis, regional enteritis, } \\
\text { insulin-dependent diabetes mellitus, thyrotoxicosis, thyroiditis, hyperthyroidism, pernicious anemia, idiopathic thrombocytopenic purpura, Addison's Disease, Behçet's Syndrome, } \\
\text { temporal arteritis, optic neuritis, asthma, chronic fatigue syndrome, congenital abnormalities (spine/skeleton), or a diagnosis/treatment for depression /mental illness. }\end{array}$} \\
\hline
\end{tabular}

examination. This comparison analysis was no different from the original crude and adjusted ORs analysis previously discussed.

\section{DISCUSSION}

The results of this study showed that the behavior of women who knew they were exposed to DES in utero but had never had a report of CIN was associated with more than the recommended number of Papanicolaou smear screenings. Diethylstilbestrol exposure was also associated with more than annual physical examinations among those without a history of a chronic disease. It appears that women exposed to DES are aware of their increased risk of such conditions, and this possibly influences their increased rate of screening procedures.
A strength of the DESAD study was its efforts to address the problem of selection bias. To reduce selection bias that may result when study respondents disproportionately include volunteers compared with a more random population-based sample, medical records were linked with live birth data for exposed and unexposed women. Exposed women were then invited to participate in the study [4]. This strategy should have minimized a selection bias that can occur when more health-conscience volunteers are participating in the study, resulting in an OR moving away from the null. Another strength of the DESAD study was its efforts to reduce loss-to-follow-up. All study sites had an interview response rate of at least $80 \%$ from the study inception, and some cohorts exceeded a $90 \%$ response rate, which is rare in any large study continuing over a period of decades. 
Study limitations included the potential for misclassification of the reported frequencies of cervical and physical examinations. Although the DESAD study had an established diagnosis verification system, in the data used for this analysis, screening examinations and health conditions were not verified by pathology or medical reports. Therefore, this study relied solely on self-report of screening and previous health conditions that were examined as potential effect-measure modifiers.

According to previous reports, women tend to overreport the frequency of cervical cancer screening [16-19]. There is no evidence to suggest that DESexposed women were more likely than unexposed women to overreport the frequency of screening examinations. However, previous data showed that DESexposed women were more likely than unexposed women to misreport their diagnoses [6]. If DES-exposed women overstated screening frequency to a greater extent than unexposed women, this would bias the OR away from the null; however, if such differential misclassification were the case, we would expect to observe positive associations for both cervical screening and GPEs, but this did not occur.

The lack of insurance information in this study may result in confounding by health-care access. If DES-exposed women were more likely than unexposed women to have insurance and therefore receive more frequent screening, then insurance status, rather than DES exposure, would be the factor that led to more frequent screening. Potential confounding could only be operating if insurance status led to more frequent screening and was more common in DES-exposed women. We attempted to address this issue of potential confounding by adjusting for education and marital status, which are highly correlated with receiving preventive care $[20,21]$ and being insured [22].

A total of $29 \%$ of DES-exposed women were not receiving annual Papanicolaou smear examinations $(\leq 2-3$ examinations in the past 5 years) as recommended by the Department of Health, Education, and Welfare; $\mathrm{NCI}$; and the American College of Obstetricians and Gynecologists [8-10]. Among the exposed women who did not meet these recommendations, $21 \%$ reported a history of CIN and 34\% reported no history of CIN. These percentages are of concern because DES-exposed women are recommended to have annual Papanicolaou smear examinations [8-10]. Future efforts should be focused on prevention by encouraging this exposed population to comply with their recommended annual cervical and vaginal screenings. Furthermore, periodic reminders from the offices of their attending gynecologists may also increase the number of their annual visits.

\section{REFERENCES}

1. Herbst AL, Ulfelder H, Poskanzer DC. Adenocarcinoma of the vagina. Association of maternal stilbestrol therapy with tumor appearance in young women. N Engl J Med $1971 ; 284: 878-81$.

2. Federal Food and Drug Administration. Diethylstilbestrol contraindicated in pregnancy. FDA Drug Bulletin. 1971.

3. O'Brien PC, Noller KL, Robboy SJ, Barnes AB, Kaufman RH, Tilley BC, et al. Vaginal epithelial changes in young women enrolled in the National Cooperative Diethylstilbestrol Adenosis (DESAD) project. Obstet Gynecol 1979;53:300-8.

4. Labarthe D, Adam E, Noller KL, O'Brien PC, Robboy SJ, Tilley BC, et al. Design and preliminary observations of National Cooperative Diethylstilbestrol Adenosis (DESAD) Project. Obstet Gynecol 1978;51:453-8.

5. Robboy SJ, Noller KL, O'Brien P, Kaufman RH, Townsend D, Barnes AB, et al. Increased incidence of cervical and vaginal dysplasia in 3,980 diethylstilbestrol-exposed young women. Experience of the National Collaborative Diethylstilbestrol Adenosis Project. JAMA 1984;252: 2979-83.

6. Hatch EE, Herbst AL, Hoover RN, Noller KL, Adam E, Kaufman RH, et al. Incidence of squamous neoplasia of the cervix and vagina in women exposed prenatally to diethylstilbestrol (United States). Cancer Causes Control 2001;12: $837-45$.

7. Kaufman RH, Adam E. Findings in female offspring of women exposed in utero to diethylstilbestrol. Obstet Gynecol 2002;99:197-200.

8. Bibbo M. Screening of individuals exposed to diethylstilbestrol. Clin Obstet Gynecol 1979;22:689-99.

9. ACOG Committee Opinion: Committee on Gynecologic Practice. Diethylstilbestrol. Int J Gynaecol Obstet 1994; 44:184.

10. Prenatal Diethylstilbestrol (DES) Exposure: Recommendations of the Diethylstilbestrol- Adenosis (DESAD) Project for the Identification and Management of Exposed Individuals. Bethesda, MD: National Cancer Institute, Office of Cancer Communications, Dept. DES, National Cancer Institute; 1980.

11. Oboler SK, LaForce FM. The periodic physical examination in asymptomatic adults. Ann Intern Med 1989;110: $214-26$.

12. Frame PS. The complete annual physical examination refuses to die. J Fam Pract 1995;40:543-5. 
13. Breslow NE, Day NE. Statistical methods in cancer research. Volume I-the analysis of case-control studies. IARC Sci Publ 1980:32:323-38.

14. Greenland S. Modeling and variable selection in epidemiologic analysis. Am J Public Health 1989;79:340-49.

15. Dwyer JH, Feinleib M, Lippert P, Hoffmeister H. Statistical models for longitudinal studies of health. New York, NY: Oxford University Press; 1991:243-6.

16. Gordon NP, Hiatt RA, Lampert DI. Concordance of self-reported data and medical record audit for six cancer screening procedures. I Natl Cancer Inst 1993;85: 566-70.

17. Sudman S, Warnecke R, Johnson T, et al. Cognitive aspects of reporting cancer prevention examinations and tests. Natl Cent Health Stat Vital Health Stat 1994;6:7.

18. Bowman JA, Redman S, Dickinson JA, Gibberd R,
Sanson-Fisher RW. The accuracy of Pap smear utilization selfreport: a methodological consideration in cervical screening research. Health Serv Res 1991;26:97-107.

19. McKenna MT, Speers M, Mallin K, Warnecke R. Agreement between patient self-reports and medical records for Pap smear histories. Am J Prev Med 1992;8:287-91.

20. Huguley CM Jr, Brown RL, Greenberg RS, Clark WS. Breast self-examination and survival from breast cancer. Cancer 1988;62:1389-96.

21. Brown AJ. Awareness and use of cervical cancer tests in a southern Appalachian community. Public Health Rep 1976; 91:236-42.

22. Hagdrup NA, Simoes EJ, Brownson RC. Health care coverage: traditional and preventive measures and associations with chronic disease risk factors. J Community Health 1997; 22:387-99. 